\title{
Mucinous nonneoplastic cyst of the pancreas penetrates the colon causing infection: a case report
}

Masashi Inoue* D, Ichiro Ohmori, Nozomi Karakuchi, Yuki Takemoto, Manabu Shimomura, Kazuaki Miyamoto, Masahiro Ikeda, Kazuhiro Toyota, Seiji Sadamoto and Tadateru Takahashi

\begin{abstract}
Background: Mucinous nonneoplastic cyst of the pancreas is a rare disease defined as a cystic lesion lined with mucinous epithelium, supported by hypocellular stroma and not communicating with the pancreatic ducts. Mucinous nonneoplastic cyst of the pancreas has no malignant potential and does not require surgical resection or surveillance. However, its preoperative differentiation from other cystic lesions of the pancreas is difficult because of several overlapping clinical, radiological, and biochemical features. We report a rare case of large mucinous nonneoplastic cyst of the pancreas in which surgery was required due to infection and the possibility of malignancy.

Case presentation: A 75-year-old Japanese man was found to have a pancreatic cyst in 2006 while undergoing postoperative evaluation for colon cancer. In 2015, the cyst ruptured, and it was treated conservatively. In 2017, he fell down on a road with a fever of $40{ }^{\circ} \mathrm{C}$ and was transported emergently to a nearby hospital. Enhanced computed tomography revealed a cystic lesion in the body of the pancreas measuring $119 \mathrm{~mm} \times 100 \mathrm{~mm}$ and an adjacent left renal cyst measuring $63 \mathrm{~mm}$ in diameter. The wall of the pancreatic cyst was thickened. Magnetic resonance imaging demonstrated a liquid surface in the pancreatic cyst. Pancreatic cyst infection was diagnosed as the source of infection. However, identification of the organism was difficult. Furthermore, due to the increase in the size and wall thickness of the cyst, it was unclear whether the cystic mass was neoplastic with malignant potential. For these reasons, the patient underwent distal pancreatectomy and splenectomy with deroofing of the left renal cyst. Intraoperatively, the pancreatic cyst adhered to the descending colon, and partial resection of the colon was added. Pathologic analysis of the resected cyst demonstrated a simple cyst lined by mucinous epithelium. There was no underlying stromal condensation or epithelial dysplasia, and communication with the native pancreatic ducts was not observed. Based on the operative and histological findings, a final diagnosis of mucinous nonneoplastic cyst of the pancreas with colonic communication was made. The colonic fistula was presumed to be the source of infection.
\end{abstract}

Conclusion: Mucinous nonneoplastic cyst of the pancreas is generally benign and requires little follow-up, but large cysts may penetrate other organs and cause severe complications.

Keywords: Pancreatic cyst, Mucinous nonneoplastic cyst (MNNC), Infection, Colon fistula

\footnotetext{
* Correspondence: inoue_masashi@hiro-hosp.jp

Department of Surgery, National Hospital Organization Higashihiroshima

Medical Center, 513 Jike, Saijo-cho, Higashihiroshima, Hiroshima 739-0041,

Japan
}

(c) The Author(s). 2019 Open Access This article is distributed under the terms of the Creative Commons Attribution 4.0 International License (http://creativecommons.org/licenses/by/4.0/), which permits unrestricted use, distribution, and reproduction in any medium, provided you give appropriate credit to the original author(s) and the source, provide a link to the Creative Commons license, and indicate if changes were made. The Creative Commons Public Domain Dedication waiver (http://creativecommons.org/publicdomain/zero/1.0/) applies to the data made available in this article, unless otherwise stated. 


\section{Introduction}

Asymptomatic pancreatic cysts are being detected with increasing frequency due to widespread use of sensitive abdominal imaging tests such as multidetector computed tomography and magnetic resonance imaging (MRI). The classification of cystic pancreatic neoplasms is generally based on differentiating mucinous from nonmucinous cysts and benign from malignant cysts [1-3].

Mucinous nonneoplastic cyst of the pancreas (MNNC) is defined as a cystic lesion lined with mucinous epithelium, supported by hypocellular stroma and not communicating with the pancreatic ducts [4]. MNNC has no malignant potential and does not require surgical resection or surveillance. However, its preoperative differentiation from mucinous neoplasms includes mucinous cystic neoplasms (MCNs) or intraductal papillary mucinous cystic neoplasms (IPMNs), and it is difficult due to several overlapping clinical, radiological, and biochemical features $[5,6]$. We report a case of MNNC in which surgery was required due to infection and the possibility of malignancy.

\section{Case presentation}

A 75-year-old Japanese man was found to have a pancreatic cyst in 2006 while undergoing postoperative evaluation for colorectal cancer. The pancreatic cyst increased in size, and surgery was recommended, but the patient declined (Fig. 1a, b). In 2015, the cyst ruptured, and he was treated conservatively (Fig. 1c, d). In 2017, he began dialysis for chronic renal failure. The same year, he fell down on a road with a fever of $40{ }^{\circ} \mathrm{C}$ and was transported emergently to a nearby hospital. Laboratory tests showed elevated levels of C-reactive protein. Serum levels of carcinoembryonic antigen and carbohydrate antigen $19-9$ were $5.8 \mathrm{ng} / \mathrm{ml}$ and $131.3 \mathrm{U} /$ $\mathrm{ml}$, respectively (Table 1 ).

The patient was treated with new quinolone-based antibiotics for 3 weeks as a conservative treatment after hospitalization. Bacteria were not detected by blood culture examination at admission. Enhanced computed tomography (CT) revealed a cystic lesion in the body of the pancreas measuring $119 \mathrm{~mm} \times 100 \mathrm{~mm}$ and an adjacent left renal cyst measuring $63 \mathrm{~mm}$ in diameter. The wall of the pancreatic cyst was thickened. The pancreatic ducts were not dilated (Fig. 2). Magnetic resonance imaging (MRI) demonstrated a liquid surface in the pancreatic cyst (Fig. 3a, b). Magnetic resonance cholangiopancreatography (MRCP) did not show pancreatic duct dilation (Fig. 3c). Endoscopic ultrasound (EUS) showed a liquid surface in the pancreatic cyst and did not show nodules in the cyst (Fig. 4). Gastroscopy showed an elevated mass in the posterior wall of the body of the stomach with intact mucosa (Fig. 5a, b). In addition, colonoscopy performed 5 months before admission showed an elevated mass in the descending colon with intact mucosa (Fig. 5c, d).

Pancreatic cyst infection was diagnosed as the source of infection. However, identification of the organism was difficult. Furthermore, due to the increase in the size and wall thickness of the cyst, it was unclear whether the cystic mass was neoplastic with malignant potential.
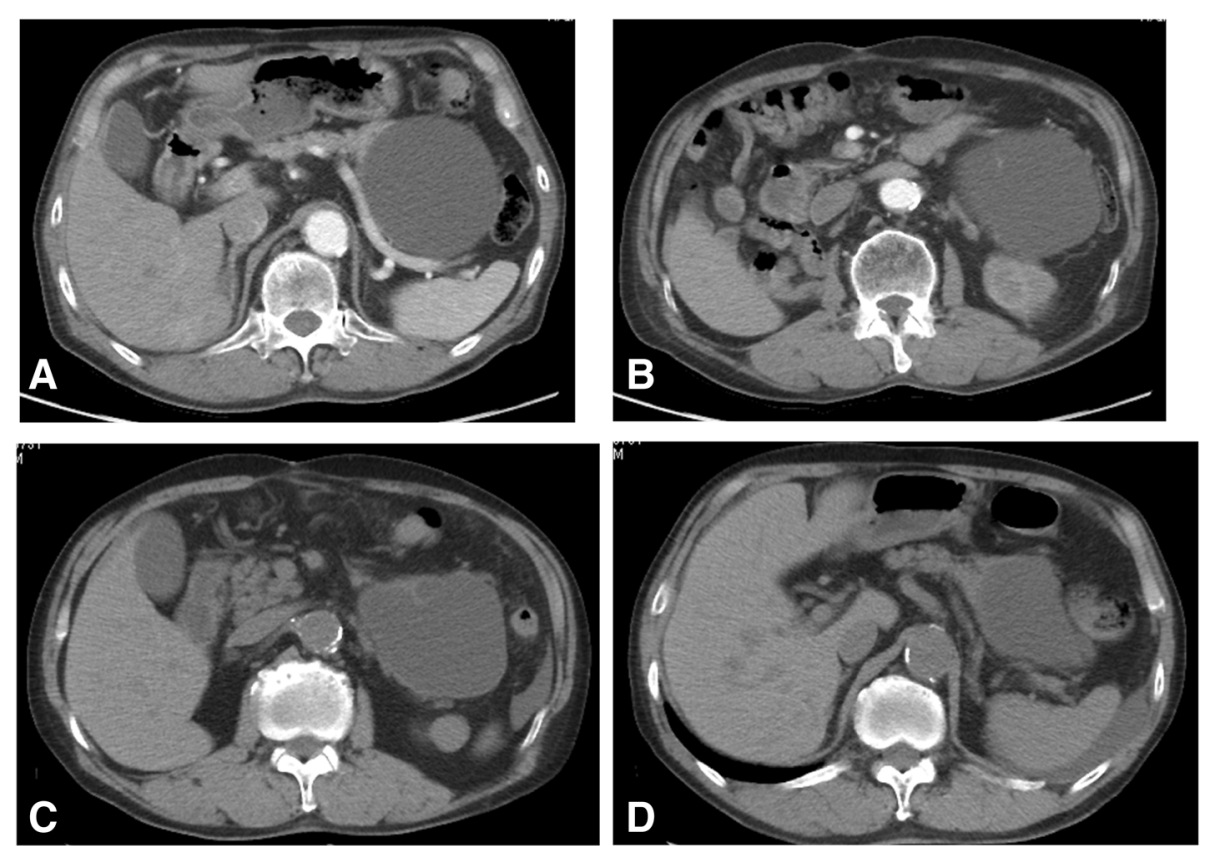

Fig. 1 Prior computed tomography findings. In 2014, the pancreatic cyst size was 103 mm (a, b). In 2015, the pancreatic cyst ruptured, and the patient was treated conservatively $(\mathbf{c}, \mathbf{d})$ 
Table 1 Blood test results at the time of admission

\begin{tabular}{|c|c|c|c|c|c|}
\hline \multicolumn{3}{|c|}{ <complete blood count> } & \multicolumn{3}{|c|}{ <biological examination> } \\
\hline WBC & 8300 & $/ \mu l$ & $\mathrm{Na}$ & 138 & $\mathrm{mEq} / \mathrm{L}$ \\
\hline RBC & $305 \times 10^{4}$ & $/ \mu l$ & K & 3.1 & $\mathrm{mEq} / \mathrm{L}$ \\
\hline $\mathrm{Hgb}$ & 10.0 & $\mathrm{~g} / \mathrm{dl}$ & $\mathrm{Cl}$ & 101 & $\mathrm{mEq} / \mathrm{L}$ \\
\hline \multirow[t]{2}{*}{ Plt } & $42.0 \times 10^{4}$ & $/ \mu l$ & T-Bil & 0.82 & $\mathrm{mg} / \mathrm{dl}$ \\
\hline & & & AST & 47 & IU/I \\
\hline \multicolumn{2}{|c|}{$<$ Tumor marker> } & & ALT & 26 & IU/I \\
\hline CEA & 5.8 & $\mathrm{ng} / \mathrm{ml}$ & BUN & 58.1 & $\mathrm{mg} / \mathrm{dl}$ \\
\hline \multirow[t]{2}{*}{ CA19-9 } & 131.3 & $\mathrm{U} / \mathrm{ml}$ & $\mathrm{Cr}$ & 6.24 & $\mathrm{mg} / \mathrm{dl}$ \\
\hline & & & $\mathrm{LDH}$ & 312 & $\mathrm{IU} / \mathrm{I}$ \\
\hline \multicolumn{2}{|c|}{$<$ Blood coagulation test $>$} & & ALP & 240 & $\mathrm{IU} / \mathrm{I}$ \\
\hline PT & 99.8 & $\%$ & $\gamma$-GTP & 12 & IU/I \\
\hline APTT & 27.9 & sec & Amylase & 27 & IU/I \\
\hline FDP & 20.5 & $\mu \mathrm{g} / \mathrm{ml}$ & Glu & 91 & $\mathrm{mg} / \mathrm{dl}$ \\
\hline D-dimer & 13.9 & $\mu \mathrm{g} / \mathrm{ml}$ & & & \\
\hline
\end{tabular}

WBC white blood cell, RBC red blood cell, Hgb hemoglobin, Plt platelet, CEA carcinoembryonic antigen, CA19-9 carbohydrate antigen 19-9, $P T$ prothrombin time, APTT activated partial thromboplastin time, FDP fibrin and fibrinogen degradation products, Na sodium, $K$ potassium, $C l$ chlorine, $T$-bil total bilirubin, AST aspartate aminotransferase, $A L T$ alanine aminotransferase, BUN blood urea nitrogen, $\mathrm{Cr}$ creatinine, $L D H$ lactate dehydrogenase, $A L P$ alkaline phosphatase, $\gamma$-GTP $\gamma$-glutamyltransferase, Glu glucose
For these reasons, the patient underwent distal pancreatectomy and splenectomy, with deroofing of the left renal cyst. Intraoperatively, the pancreatic cyst strongly adhered to the descending colon, so partial resection of the colon was added.

Pathologic analysis of the resected cyst demonstrated a simple cyst lined by mucinous epithelium (Fig. 6b). There was no underlying stromal condensation or epithelial dysplasia, and communication with the native pancreatic ducts was not observed. Pathological analysis of the resected colon adhesive pancreatic wall revealed a fistulalike depression on the mucosal side of the colon (Fig. 6c). Bacteroides fragilis and Streptococcus sanguinis were detected as a result of culture examination of the pancreatic cyst contents. On the basis of the operative and histological findings, a final diagnosis of MNNC with colon communication was made (Fig. 6). The small colonic fistula was presumed to be the source of infection.

Postoperatively, the patient was treated for a grade $B$ pancreatic fistula. On postoperative day 12, emergency surgery was performed for thrombotic descending colon perforation. On postoperative day 94, the patient was discharged on foot.

\section{Discussion}

We describe a case of a large MNNC that eroded into the colon, leading to cyst infection. MNNC is an increasingly recognized subset of pancreatic cysts. In 2002, Kosmahl et al. [7] reported a new type of nonneoplastic
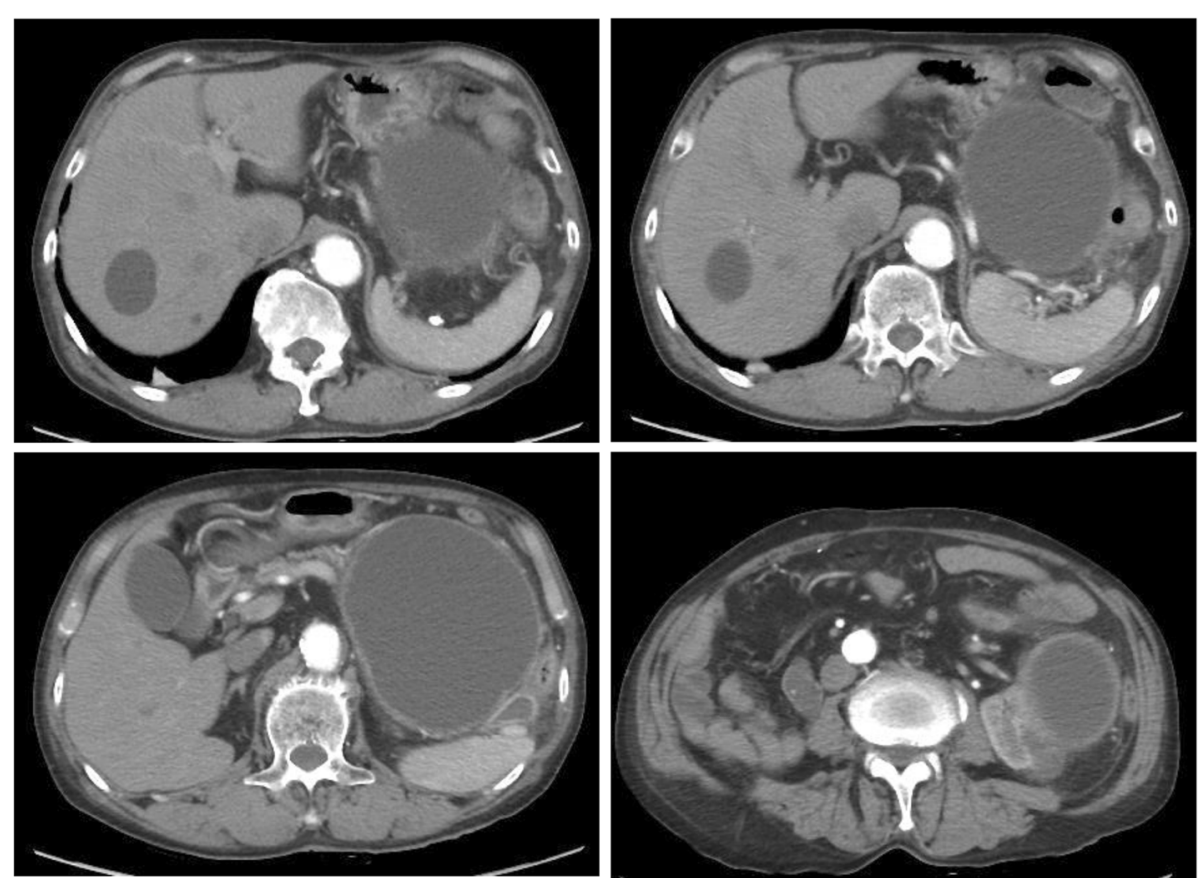

Fig. 2 Computed tomography (CT) findings. Enhanced CT revealed a cystic lesion in the body of the pancreas measuring $119 \mathrm{~mm} \times 100 \mathrm{~mm}$ and an adjacent left renal cyst of $63 \mathrm{~mm}$ in diameter. The pancreas cyst wall was thickened. The pancreatic ducts were not dilated 

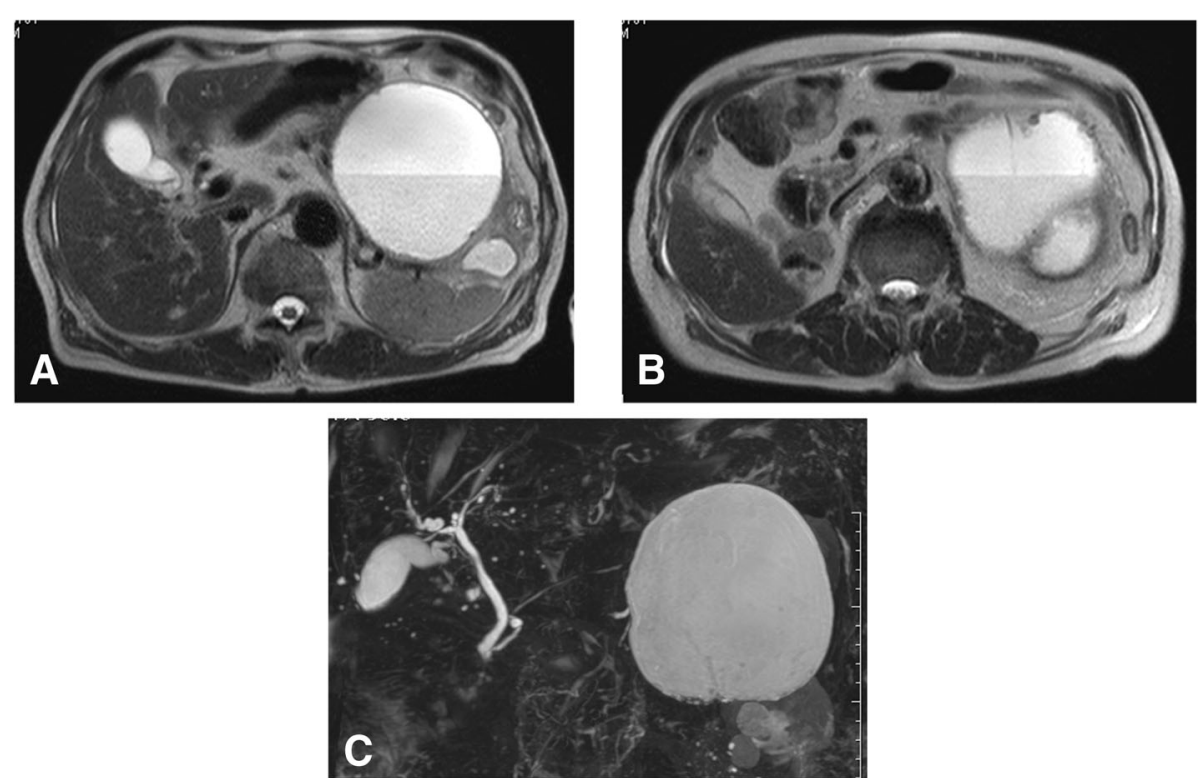

Fig. 3 Magnetic resonance imaging (MRI) findings. MRI demonstrated a liquid surface in the pancreatic cyst (a, b). The cyst contained mucinous components suggesting infection. Magnetic resonance cholangiopancreatography did not show pancreatic duct dilation (c)

cystic lesion of the pancreas, designated as MNNC, in five patients. Later, 21 more cases were reported [8-11]. The incidence of MNNC has been reported as $2.1-3.4 \%$ in resected pancreatic lesions [8, 9]. MNNC has no malignant potential and does not require surgical resection or surveillance. MNNC is pathologically distinct from MCN in that it lacks an ovarian-type stroma, cellular atypia, and communication with the pancreatic ductal system distinctive of IPMN. Its preoperative differentiation from MCN or IPMN presents a diagnostic challenge due to several overlapping clinical, radiological, and biochemical features. Fisher et al. [12] studied the accuracy of CT in predicting the malignant potential of cystic pancreatic neoplasms in 48 patients. The authors found that CT diagnosis was accurate in $39 \%$ of cases. Visser et al. [13] reported on the relative accuracy of CT and MRI in the characterization of pancreatic cysts in 58 patients and showed that there was a substantial rate of misdiagnosis (54-57\%). Another study compared the performance of $\mathrm{CT}$ and MRI/MRCP in the characterization of small pancreatic cysts in 30 patients [14]. MRI enabled more confident assessment of cyst morphology, but the accuracy of both imaging techniques for cyst characterization was comparable (71-84\%). Diagnosis of cyst contents has been attempted, but it has not yet been reliably successful.

In our patient's case, the cyst was previously identified on the basis of CT in 2006. Surgery was recommended
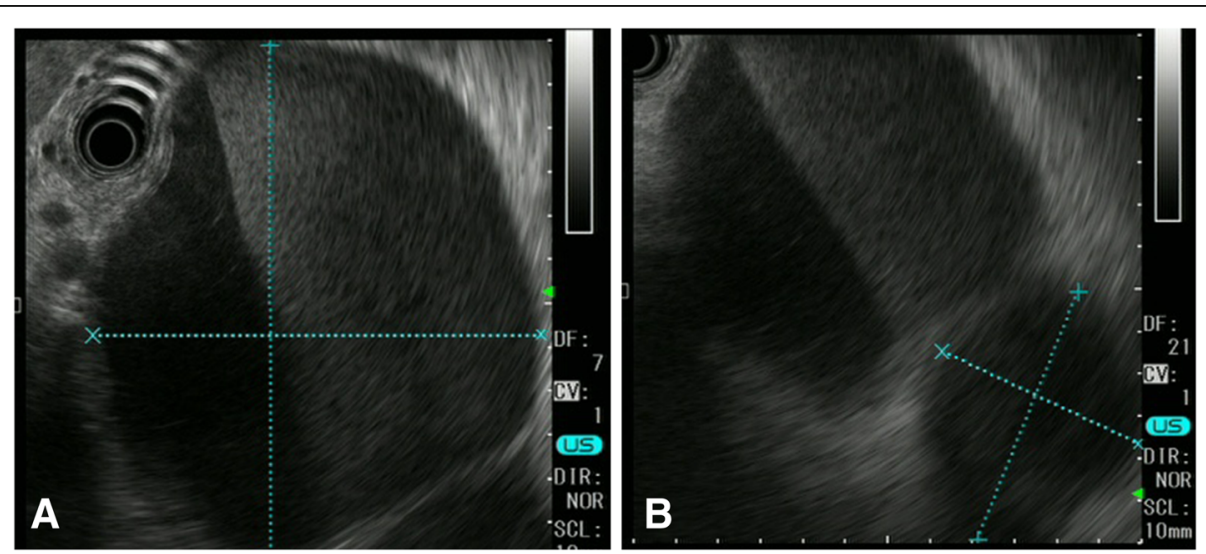

Fig. 4 Endoscopic ultrasound (EUS) findings. a Pancreatic cyst. b Right renal cyst. EUS showed a liquid surface in the pancreatic cyst and did not show nodules in the cysts 

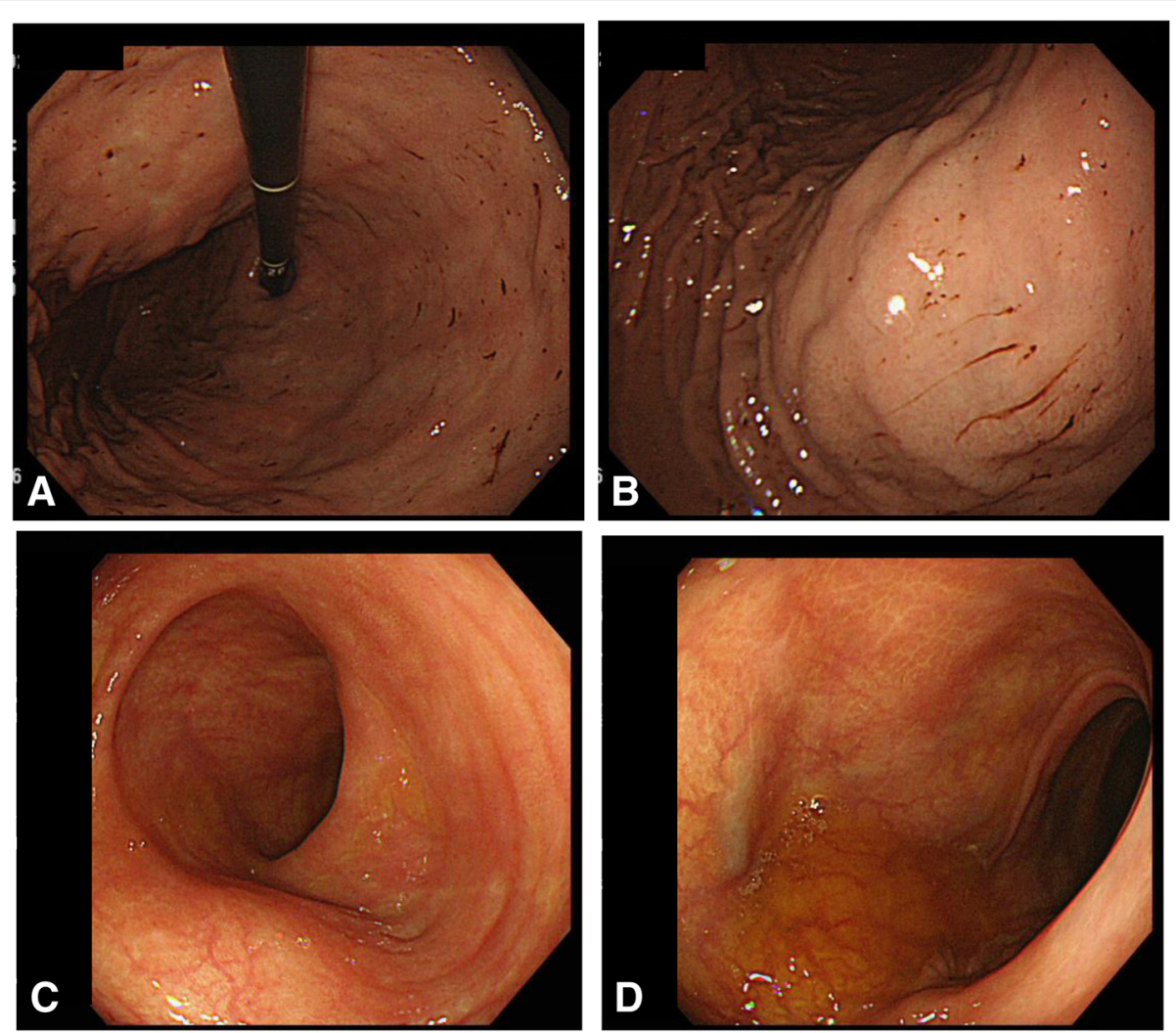

Fig. 5 Endoscopy findings. Gastroscopy showed an elevated mass in the posterior wall of the body of the stomach with intact mucosa (a, b) Colonoscopy showed an elevated mass in the descending colon with intact mucosa (c, d)

A

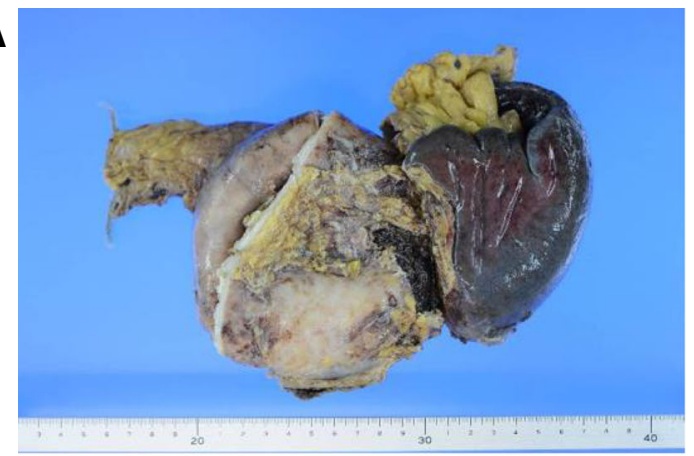

B

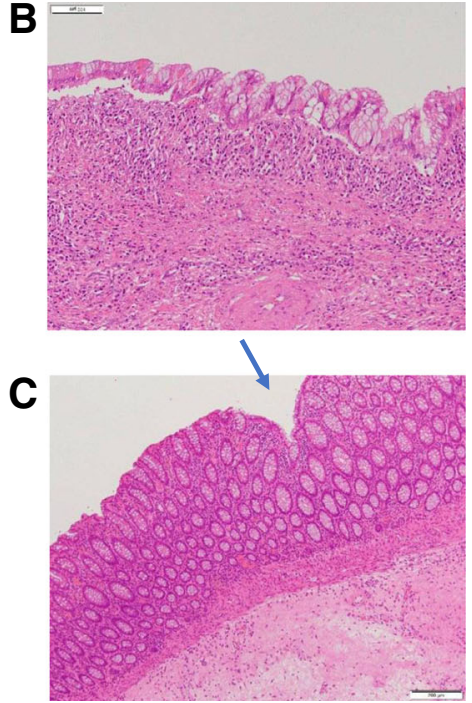

Fig. 6 Pathologic analysis. a Macroscopic findings. b Microscopic findings of pancreas cyst wall. c Microscopic findings of colon mucosa. Pus accumulated inside the pancreatic cyst and renal cyst. The cyst was a simple cyst lined by mucinous epithelium. There was no underlying stromal condensation or epithelial dysplasia. Communication with the native pancreatic ducts was not observed. The resected colon adhesive pancreatic wall revealed a fistula-like depression on the mucosal side of the colon ( $)$.Mucinous nonneoplastic cyst of the pancreas fistula to the colon was the presumed source of infection 
at that time because the cyst was difficult to distinguish from a malignancy, but the patient refused. The cyst later ruptured and then developed a cryptic infection requiring extensive surgery.

We are aware of no prior case reports of MNNC and colonic fistula. However, severe acute pancreatitis can lead to localized complications such as the formation of a pseudocyst, necrosis, or an abscess. Acute pancreatitis complications with colonic involvement have a relatively low incidence of approximately 3\% [15]. Fistula formation is thought to be due to elevated internal pressure from fluid accumulation within the pseudocyst and proteolytic enzymes within the fluid that invade adjacent organs, inducing ischemic changes that enable penetration of the walls of the most vulnerable organs and formation of a fistula [16]. Most pseudocyst enteric fistulas that form in the upper gastrointestinal tract can be treated conservatively and have a relatively good prognosis. In contrast, fistulas that form in the colon rarely heal spontaneously and tend to be associated with fatal complications, with a reported mortality of approximately $17-67 \%$ [17].

In our patient's case, it was presumed that the increased MNNCs were in communication with the colon, resulting in a small colon fistula through which enteric bacteria could pass, causing a cystic infection. CT revealed increased pancreatic cyst size and wall thickness. MRI suggested a mucinous component of the cyst. It was difficult to evaluate the whole cyst in detail by EUS. For these reasons, we were unable to rule out malignancy and chose to proceed with surgical resection. Surgical intervention allows for complete removal of the cyst and provides tissue for an accurate histological diagnosis.

Because the cyst communicated with the descending colon, a partial resection of the colon was also performed. It is possible that ischemic changes caused by the resection led to the subsequent colonic rupture. The colon rupture was unpredictable as a postoperative complication, but it should be considered when similar cases are seen in the future.

\section{Conclusion}

This was a case of a large MCCN that caused a fistula to the descending colon, through which the cyst became infected. MCCN is generally benign and requires little follow-up, but large cysts may penetrate other organs and cause severe complications.

\section{Abbreviations}

CT: Computed tomography; EUS: Endoscopic ultrasound; IPMN: Intraductal papillary mucinous cystic neoplasm; MCN: Mucinous cystic neoplasm; MNNC: Mucinous nonneoplastic cyst of the pancreas; MRCP: Magnetic resonance cholangiopancreatography; MRI: Magnetic resonance imaging

\section{Authors' contributions}

$\mathrm{Ml}$ wrote the manuscript. $\mathrm{MI}$ and $\mathrm{IO}$ designed the study. NK, YT, MS, KM, MI, $\mathrm{KT}, \mathrm{SS}$, and $\Pi \mathrm{T}$ proofread the manuscript. All authors read and approved the final manuscript.

Funding

The authors declare no conflicts of interest associated with this report.

\section{Availability of data and materials}

The datasets generated during the current study available from the corresponding author on reasonable request.

\section{Ethics approval and consent to participate}

This study was approved by the institutional review board, and written informed consent was obtained from the patient.

\section{Consent for publication}

Written informed consent was obtained from the patient for publication of this case report and any accompanying images. A copy of the written consent is available for review by the Editor-in-Chief of this journal.

\section{Competing interests}

The authors declare that they have no competing interests.

Received: 29 October 2018 Accepted: 11 June 2019

Published online: 10 August 2019

\section{References}

1. Tanaka M, Chari S, Adsay V, Fernandez-del Castillo C, Falconi M, Shimizu M, et al. International consensus guidelines for management of intraductal papillary mucinous neoplasms and mucinous cystic neoplasms of the pancreas. Pancreatology. 2006;6:17-32.

2. Khalid A, Brugge W. ACG practice guidelines for the diagnosis and management of neoplastic pancreatic cysts. Am J Gastroenterol. 2007; 102:2339-49.

3. Shen J, Brugge WR, Dimaio CJ, Pitman MB. Molecular analysis of pancreatic cyst fluid: a comparative analysis with current practice of diagnosis. Cancer. 2009;117:217-27.

4. Hruban RH, Pitman MB, Klimstra DS. Tumors of the pancreas. In: Hahn KS, editor. Atlas of tumor pathology (4th series). 6th ed. Washington, DC: American Registry of Pathology; 2007. p. 358-60.

5. Nadig SN, Pedrosa I, Goldsmith JD, Callery MP, Vollmer CM. Clinical implications of mucinous nonneoplastic cysts of the pancreas. Pancreas. 2012:41:441-6.

6. Khashab MA, Kim K, Lennon AM, Shin EJ, Tignor AS, Amateau SK, et al. Should we do EUS/FNA on patients with pancreatic cysts? The incremental diagnostic yield of EUS over CT/MRI for prediction of cystic neoplasms. Pancreas. 2013:42:717-21.

7. Kosmahl M, Egawa N, Schröder S, Carneiro F, Lüttges J, Klöppel G. Mucinous nonneoplastic cyst of the pancreas: a novel nonneoplastic cystic change? Mod Pathol. 2002;15:154-8.

8. Cao W, Adley BP, Liao J, Lin X, Talamonti M, Bentrem DJ. et al. Mucinous nonneoplastic cyst of the pancreas: apomucin phenotype distinguishes this entity from intraductal papillary mucinous neoplasm. Hum Pathol. 2010:41:513-21.

9. Kosmahl M, Pauser U, Peters K, Sipos B, Lüttges J, Kremer B, et al. Cystic neoplasms of the pancreas and tumor-like lesions with cystic features: a review of 418 cases and a classification proposal. Virchows Arch. 2004:445:168-78.

10. Brunner A, Ladurner R, Kosmahl M, Mikuz G, Tzankov A. Mucinous nonneoplastic cyst of the pancreas accompanied by non-parasitic asymptomatic liver cysts. Virchows Arch. 2004;444:482-4

11. Goh BK, Tan YM, Tan PH, Ooi LL. Mucinous nonneoplastic cyst of the pancreas: a truly novel pathological entity? World J Gastroenterol. 2005: 11:2045-7.

12. Fisher WE, Hodges SE, Yagnik V, Morón FE, Wu MF, Hilsenbeck SG, et al. Accuracy of $C T$ in predicting malignant potential of cystic pancreatic neoplasms. HPB (Oxford). 2008;10:483-90.

13. Visser BC, Yeh BM, Qayyum A, Way LW, McCulloch CE, Coakley FV. Characterization of cystic pancreatic masses: relative accuracy of $C T$ and MRI. AJR Am J Roentgenol. 2007;189:648-56. 
14. Sainani NI, Saokar A, Deshpande V, Fernández-del Castillo C, Hahn P, Sahani DV. Comparative performance of MDCT and MRI with MR

cholangiopancreatography in characterizing small pancreatic cysts. AJR Am J Roentgenol. 2009;193:722-31.

15. Mohamed SR, Siriwardena AK. Understanding the colonic complications of pancreatitis. Pancreatology. 2008;8:153-8.

16. Suzuki A, Suzuki S, Sakaguchi T, Oishi K, Fukumoto K, Ota S, et al. Colonic fistula associated with severe acute pancreatitis: report of two cases. Surg Today. 2008;38:178-83.

17. Wille-Jørgensen P, Frederiksen HJ. Colonic necrosis or fistula following pancreatitis or gastric surgery. Eur J Surg. 1991;157:137-9.

\section{Publisher's Note}

Springer Nature remains neutral with regard to jurisdictional claims in published maps and institutional affiliations.

Ready to submit your research? Choose BMC and benefit from:

- fast, convenient online submission

- thorough peer review by experienced researchers in your field

- rapid publication on acceptance

- support for research data, including large and complex data types

- gold Open Access which fosters wider collaboration and increased citations

- maximum visibility for your research: over $100 \mathrm{M}$ website views per year

At BMC, research is always in progress.

Learn more biomedcentral.com/submissions 